\title{
Identification of novel deep intronic PAH gene variants in patients with phenylketonuria
}

\author{
Xiaohua Jin ${ }^{1}$, Yousheng Yan ${ }^{2}$, Chuan Zhang ${ }^{3}$, Ya Tai ${ }^{4}$, Lisha An ${ }^{1}$, Xinyou Yu ${ }^{5}$, Linlin \\ Zhang ${ }^{6}$, Xiaofang $\mathrm{Cao}^{7}$, Shengju $\mathrm{Hao}^{3}$, Chenghong $\mathrm{Yin}^{2}$, and $\mathrm{Xu} \mathrm{MA}{ }^{8}$ \\ ${ }^{1}$ National Research Institute for Family Planning \\ ${ }^{2}$ Capital Medical University Beijing Obstetrics and Gynecology Hospital \\ ${ }^{3}$ Gansu Provincial Maternity and Child-Care Hospital \\ ${ }^{4}$ Peking University International Hospital \\ ${ }^{5}$ General Hospital of Ningxia Medical University \\ ${ }^{6}$ The Third Affiliated Hospital of Zhengzhou University \\ ${ }^{7}$ National Research Institute for Family Planning Center for Genetics \\ ${ }^{8}$ National Research Institute for Family Planning, Peking Union Medical College
}

January 3, 2021

\begin{abstract}
Phenylketonuria (PKU) is caused by phenylalanine hydroxylase (PAH) gene variants. Previously, 94.21\% of variants were identified using Sanger sequencing and multiplex ligation-dependent probe amplification. To investigate the remaining variants, whole-genome sequencing (WGS) was performed in four patients with PKU with unknown genotype to identify deep intronic or structural variants. Three novel heterozygous variants (c.706+368T $>$ C; c. 1065+241C >A; and c.1199+502A $>$ T) were identified in a deep PAH gene intron. The c. $1199+502 \mathrm{~A}>\mathrm{T}$ variant was detected in $60 \%(6 / 10) \mathrm{PKU}$ patients. In silico prediction showed that the three deep variants may impact splice site selection and result in inclusion of a pseudo-exon. The c.1199+502A $>\mathrm{T}$ PAH minigene and reverse transcription PCR of blood RNA in a patient with PKU and compound heterozygous variants $($ c. $1199+502 \mathrm{~A}>\mathrm{T} / \mathrm{c} .1199 \mathrm{G}>\mathrm{A})$ confirmed that the c.1199+502A $>\mathrm{T}$ variant creates a novel branch point and leads to the inclusion of a 25 bp in PAH mRNA (r.1199_2000ins1199+538_1199+562). Furthermore, the c.1199G $>$ A mutation leads to the retention of an additional $17 \mathrm{nt}$ in the PAH mRNA transcript (r.1199_2000ins1199+1_1199+17). These results expand the PAH genotypic spectrum and highlight that deep intronic analysis of PAH can improve genetic diagnosis in undiagnostic patients.
\end{abstract}

\section{Hosted file}

Manuscript- humu-2020-0465.pdf available at https://authorea.com/users/386819/articles/ 502273-identification-of-novel-deep-intronic-pah-gene-variants-in-patients-withphenylketonuria 


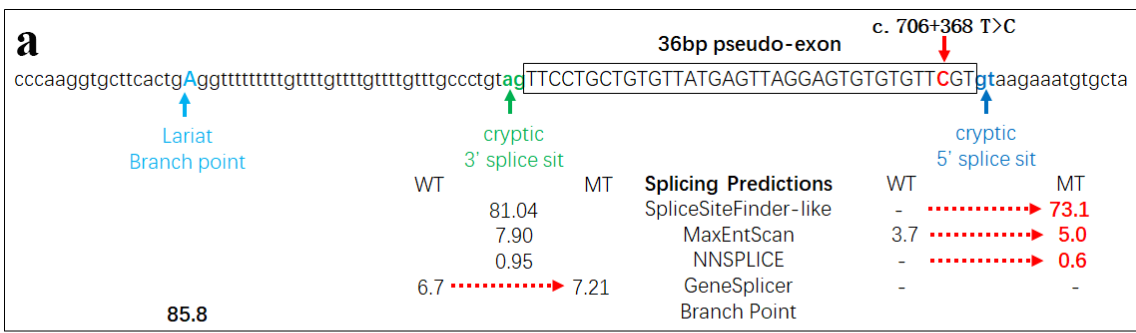

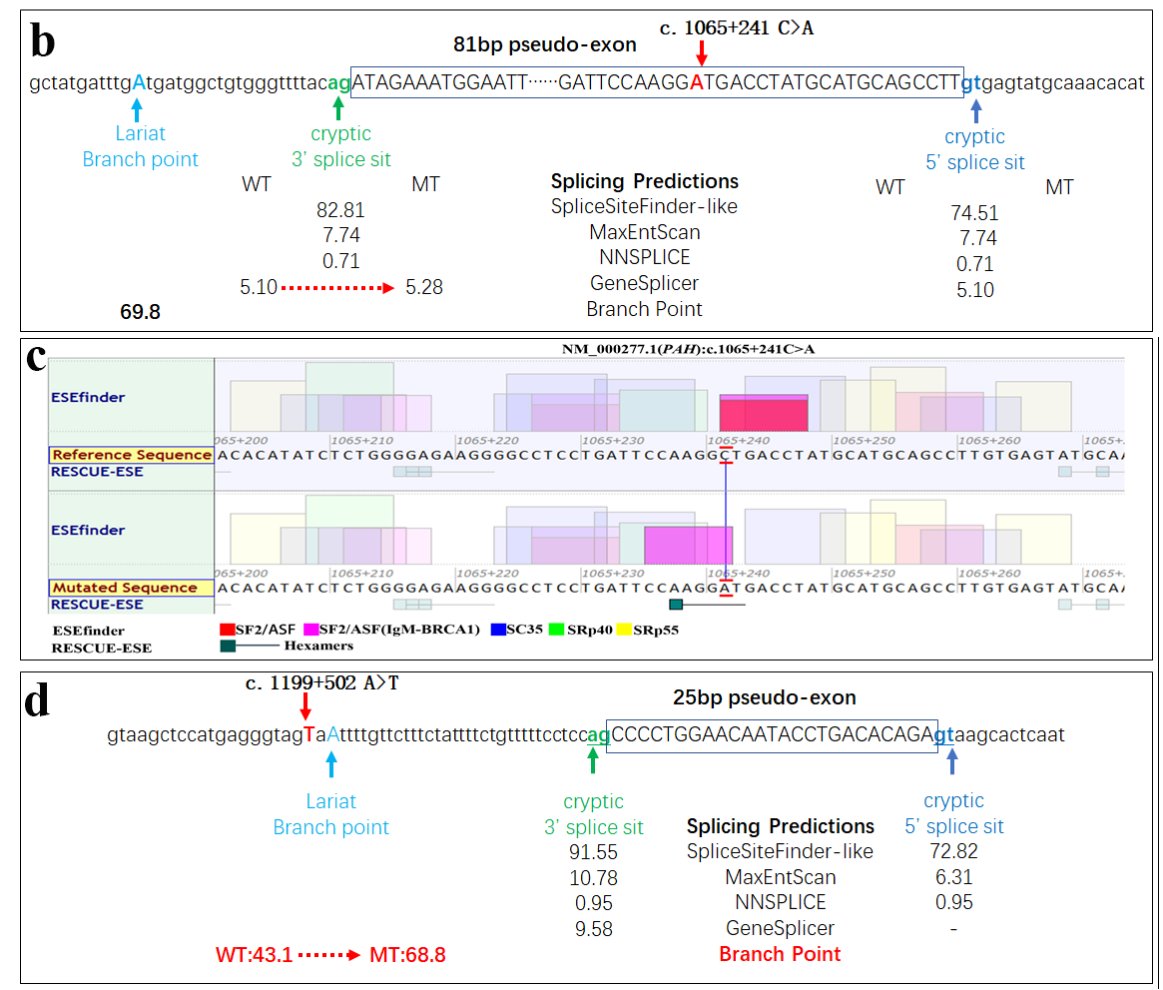




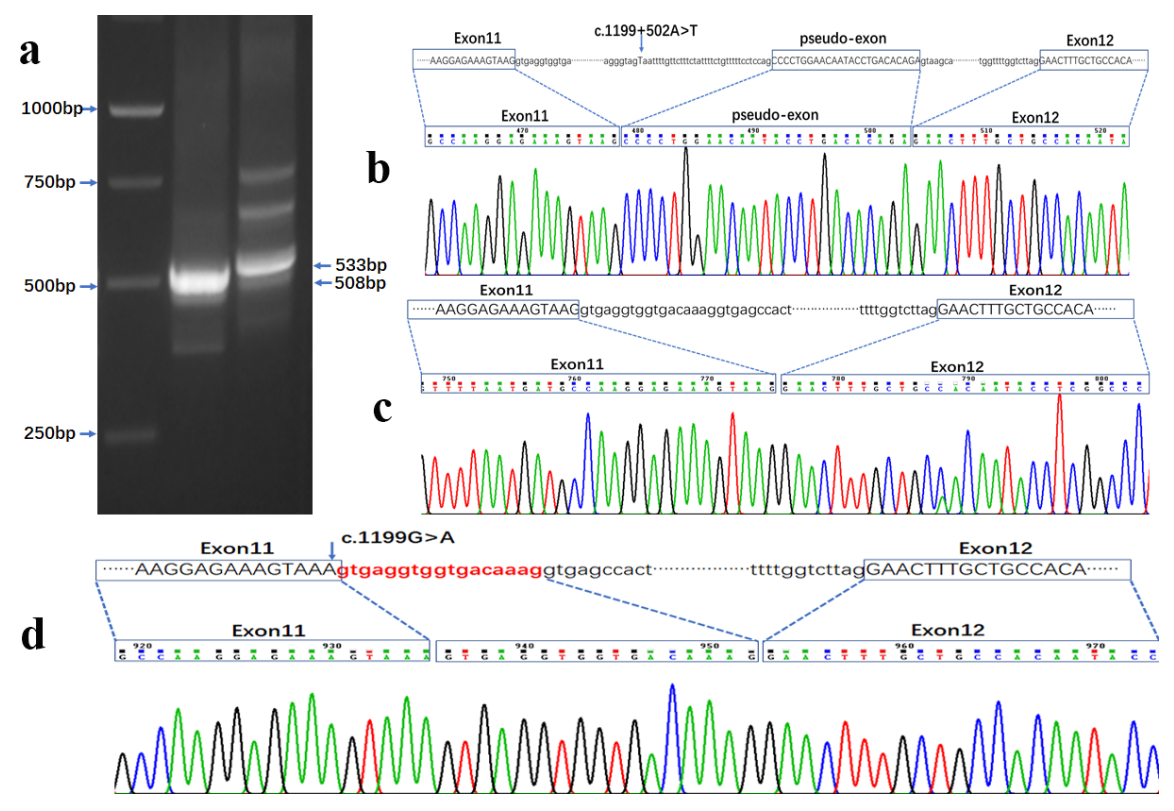

\section{Hosted file}

Table 1.pdf available at https://authorea.com/users/386819/articles/502273-identification-ofnovel-deep-intronic-pah-gene-variants-in-patients-with-phenylketonuria 